\title{
Controlled-release approaches towards the chemotherapy of tuberculosis
}

\author{
This article was published in the following Dove Press journal: \\ International Journal of Nanomedicine \\ II October 2012 \\ Number of times this article has been viewed
}

\section{Bullo Saifullah' \\ Mohd Zobir B Hussein ${ }^{1,2}$ \\ Samer Hasan Hussein Al Ali' \\ 'Department of Chemistry, Faculty of Science, Universiti Putra Malaysia, Serdang, Selangor, Malaysia; ${ }^{2}$ Advanced Materials and Nanotechnology Laboratory, Institute of Advanced Technology, Universiti Putra Malaysia, Serdang, Selangor, Malaysia}

\begin{abstract}
Tuberculosis (TB), caused by the bacteria Mycobacterium tuberculosis, is notorious for its lethality to humans. Despite technological advances, the tubercle bacillus continues to threaten humans. According to the World Health Organization's 2011 global report on TB, 8.8 million cases of TB were reported in 2010, with a loss of 1.7 million human lives. As drugsusceptible TB requires long-term treatment of between 6 and 9 months, patient noncompliance remains the most important reason for treatment failure. For multidrug-resistant TB, patients must take second-line anti-TB drugs for 18-24 months and many adverse effects are associated with these drugs. Drug-delivery systems (DDSs) seem to be the most promising option for advancement in the treatment of TB. DDSs reduce the adverse effects of drugs and their dosing frequency as well as shorten the treatment period, and hence improve patient compliance. Further advantages of these systems are that they target the disease area, release the drugs in a sustained manner, and are biocompatible. In addition, targeted delivery systems may be useful in dealing with extensively drug-resistant TB because many side effects are associated with the drugs used to cure the disease. In this paper, we discuss the DDSs developed for the targeted and slow delivery of anti-TB drugs and their possible advantages and disadvantages.
\end{abstract}

Keywords: Mycobacterium tuberculosis, drug-delivery system, targeted delivery, anti-TB drug, TB, patient compliance

\section{Introduction}

Tuberculosis (TB), caused by the bacterium Mycobacterium tuberculosis, remains a most lethal disease in humans. The tubercle bacillus has tremendous ability to cope with the human immune system and has developed the ability to survive and do well within macrophage phagosomes. Despite technological advances, TB continues to threaten humans. According to the World Health Organization's 2011 global report on TB 2011 World Health Organization (WHO) report, ${ }^{1} 8.8$ million TB cases were reported in this year, approximately 1.35 million of which were fatal with an additional 0.35 million fatalities in individuals with HIV. TB remains among the three major causes of death among females aged 15-44 years old and approximately 320,000 women died due to TB in 2010. The identification and suitable treatment of multidrug-resistant TB (MDR-TB) remain the most important aspects to be addressed. Furthermore, TB's resistance to contemporary TB antibiotics is due to its dormant form in the host cells. It is known that rifampin, isoniazid, and ethambutol (but not pyrazinamide) require bacteria to reproduce in order to perform their function. It is thought that the bacteria's ability to remain dormant allows them to be phenotypically resistant to prescribed antibiotics..$^{2,3}$
Correspondence: Mohd Zobir B Hussein Department of Chemistry, Faculty of Science, Universiti Putra Malaysia, 43400 UPM, Serdang, Selangor, Malaysia $\mathrm{Tel}+6038946680 \mathrm{I}$

Fax +60389435380

Email mzobir@science.upm.edu.my 
As is well known, drug development is a very long process requiring significant funding and much effort. At the end of the process, it is often still not clear whether the target drug is safe for humans, thus there has been no new anti-TB drug on the market for almost five decades. Researchers are therefore increasingly drawn to biocompatible drug-delivery systems (DDSs) as they can be fabricated to target the specific site of disease, thus reduce side effects in healthy tissues, and prevent drug degradation in transit to the target site. Furthermore, DDSs can maintain the same or a higher level of therapeutic effect using the same - or even, in some cases, a lower - quantity of drug. Most importantly, the developed DDSs can be used for newly developed drugs. Many DDSs have been developed for anti-TB drugs. They can be classified either by type of system - such as biocompatible organic polymer, inorganic, organic-inorganic hybrid, and dendrimer - or they can be classified according to their size - for example, macro, micro, and nano material. In this review, we review some of the most important systems.

\section{Types of tuberculosis}

TB can be categorized into one of three main types: drugsusceptible TB (DS-TB), multidrug-resistant TB (MDR-TB), or extensively drug-resistant TB (XDR-TB).

\section{DS-TB}

DS-TB is the most common form of TB and is susceptible to the four first-line medicines: rifampin, isoniazid, ethambutol, and pyrazinamide. Table 1 shows the molecular structure of each of these first-line drugs.

\section{MDR-TB}

It is very difficult to treat TB that has become resistant to multiple drugs, especially to more powerful drugs such as isoniazid and rifampin. MDR-TB escalates from drug resistant TB bacteria and/or from the consequences of mismanagement of the prescribed first-line medicines. ${ }^{4}$ The key factor in the emergence of MDR-TB is the mismanagement of the desired course of therapy and/or a weak county-wide plan. ${ }^{5}$ To deal with MDR-TB, second-line medicines such as para-aminosalicylic acid, amino glycosides, cycloserine, fluoroquinolones, thioamides, and cyclopeptides are employed. However, these second-line treatments may have adverse effects, the duration of treatment might be considerable, and their cost is about 100 times more than that of first-line therapies. MDR-TB can also develop resistance to second-line drugs thus making the situation more complicated.

\section{XDR-TB}

The worst circumstance occurs in the form of XDR-TB. In this type of TB, the bacteria develop resistance against isoniazid and rifampin along with essential second-line drugs - that is, any of the fluoroquinolones and three injectable therapies, amikacin, kanamycin, and capreomycin. XDR-TB can also become resistant to other medicines, making the treatment more difficult. A person can also become the victim of XDR-TB by obtaining the XDR bacteria from a person already suffering from XDR-TB.

\section{Macrophages and survival mechanism of tuberculosis bacteria in macrophages Macrophages}

Macrophages (white blood cells) are the human defense against pathogens. Macrophages work equally well in unspecified action (innate immunity) and in assisting in the initiation of particular resistive action (adaptive immunity) of vertebrate species. Their mode of action is to take in and excrete leftover cells and pathogens after destroying them; they can work both as standing or moving units. Further, macrophages signal lymphocytes and other defensive units to take action against pathogens. Phagocyte units are specialized in assailing alien materials, contagious pathogens, and cancerous cells through a destructive mode of action. ${ }^{6}$ Figure 1 shows the detailed structure of a macrophage and a typical phagocytosis process.

Table I Structures of first-line antituberculosis drugs

Rifampin (RIF) Isoniazid




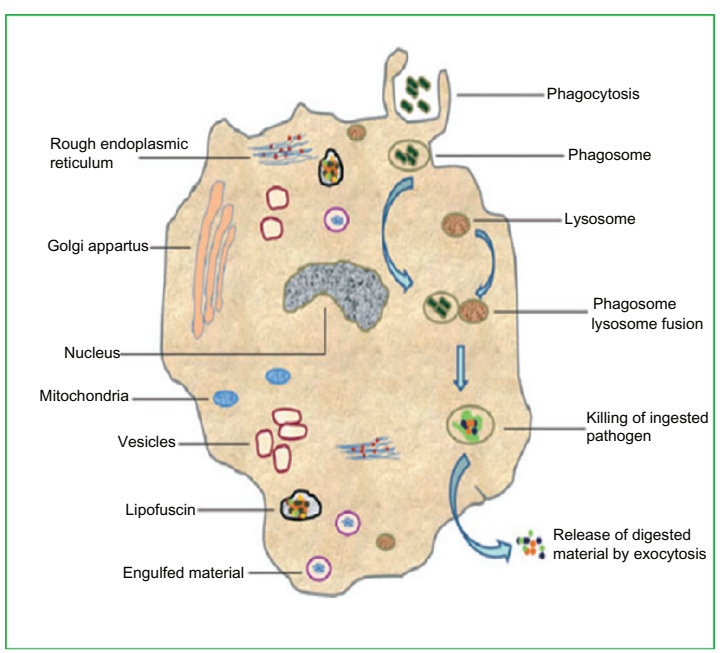

Figure I Detailed structure of a macrophage showing a typical process of phagocytosis.

Meena LS, Rajani. Survival mechanisms of pathogenic Mycobacterium tuberculosis H37Rv. FEBS J. 2010;277(II):24I6-2427. Reproduced with permission from John Wiley and Sons. ${ }^{8}$

\section{The survival mechanisms of TB in macrophages}

Bacteria of the Mycobacterium genus have evolved several mechanisms to avoid the antagonistic surroundings of the macrophages (the chief host units for the TB). ${ }^{7}$ The mechanisms employed by the TB are thoroughly reviewed by Meena and Rajani. ${ }^{8}$ Four of the mechanisms - inhibition of phagosome-lysosome fusion, inhibition of phagosomal acidification, protection against oxidative radicals, and the tryptophan aspartate-containing coat (TACO) protein on the phagosome wall - are outlined in Figure 2. ${ }^{8}$

\section{Inhibition of phagosome-lysosome fusion}

Growth inhibition and the killing of intracellular pathogens within the mononuclear phagocyte lineage host cell are considered to depend on phagosome-lysosome fusion. ${ }^{9}$ M. tuberculosis is able to escape phagosome-lysosome fusion, hence avoids lysosomal killing.

\section{Inhibition of phagosomal acidification}

Vacuoles having Mycobacterium avium (type of mycobacterial infection) are not as acidic as nearby lysosomes. ${ }^{10,11}$ The lack of a vesicular proton-ATPase pump means that phagosomes within M. avium are not acidified. This inhibition of phagosomal acidification enables the bacterium to cope with the hostile environment of macrophages. ${ }^{12}$

\section{Protection against oxidative radicals}

Highly reactive species such as oxygen and nitrogen radicals are produced in macrophages to destroy the intracellular bacteria. One of the proteins of the Erdman strain of M. tuberculosis

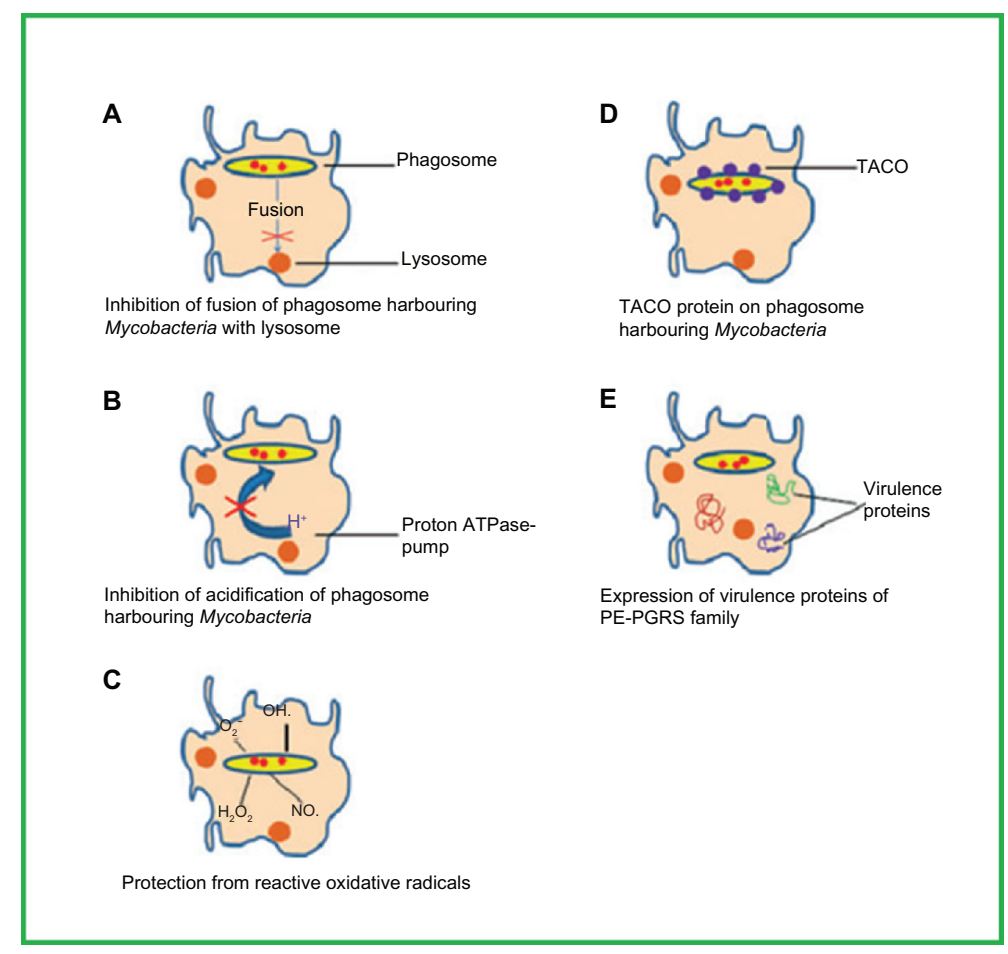

Figure 2 Important factors of the survival mechanisms involved in the phagosome maturation arrest of Mycobacterium tuberculosis inside the macrophages. Meena LS, Rajani. Survival mechanisms of pathogenic Mycobacterium tuberculosis H37Rv. FEBS J. 2010;277(II):24I6-2427. Reproduced with permission from John Wiley and Sons. ${ }^{8}$

Abbreviation: TACO, tryptophan aspartate-containing coat. 
cyclopropanates the double bonds of mycolic acid, resulting in a ten-times lower susceptibility to peroxides. ${ }^{13}$

\section{TACO on the phagosome wall}

Bacterial delivery to lysosomes is prevented by the TACO on the wall of phagosomes. TACO retained on the phagosome wall permits Mycobacterium spp. to escape the bactericidal action of macrophages. ${ }^{7}$

\section{Responding to TB intelligently (with limited chemotherapy options)}

The key remedial tactic for dealing with the TB is to improve patient compliance by reducing drug toxicity and ensuring therapy is patient friendly. ${ }^{5}$ DDSs seem to be the one of the best options in both these respects. ${ }^{8}$ DDSs offer a tremendous way to avoid the adverse consequences associated with TB medicines, especially second-line drugs, by not exposing the drugs to healthy tissues.

As already noted, many adverse effects are associated with prescribed TB medicines. A summary of the side effects of TB chemotherapy is given in Tables 2 and 3. ${ }^{14-16}$ Anaphylaxis, allergic reaction (eg, exfoliative dermatitis, Steven-Johnson syndrome), severe gastritis with bleeding, hepatitis, and renal collapse are the life-threatening undesirable effects of the chemotherapy and in such circumstances treatment is stopped. ${ }^{16,17}$

Patient outcomes must be improved by minimizing cytotoxicity to both the affected and healthy tissues and increasing patient compliance. ${ }^{15}$ Thus, drug-delivery vehicles either have to target the place of infection or reduce the dosing frequency of drugs. ${ }^{15}$ There is an urgent need for uninterrupted efforts to develop drug-delivery vehicles that are patient friendly. Nanoscaled chemotherapy would permit the uptake of medicine to be decreased, hence allow better execution of chemotherapy in TB. ${ }^{18}$

\section{DDSs for chemotherapy of tuberculosis}

Currently, the focus of research is on the development of new anti-TB drugs; however, as previously noted, drug development is a lengthy process and no new anti-TB drug has been introduced in the last five decades. A more appropriate strategy would be to make more effective and deliberate use of the anti-TB drugs currently available. Therefore, DDSs should be the prime focus of TB research because they can enhance efficacy and minimize the side effects, dosage frequency, and treatment period.

Various approaches have been trialed by researchers in the area of sustained and targeted release of TB medicines, especially the use of nanoparticle DDSs for second-line anti-TB drugs. This review will now examine the advantages of various DDSs, especially nanoparticle DDSs, in the chemotherapy of tuberculosis and summarize the challenges in their implementation. Further, as nanotechnology has considerable potential in vaccination and other curative schemes against TB and other transferable pathogens, its benefits in the treatment of TB will also be explored. ${ }^{19,20}$

Sosnik et $\mathrm{al}^{21}$ have thoroughly reviewed the application of nanoscience and various nanoscaled DDSs in the treatment of tuberculosis, examining, among others, nanoemulsions, niosomes, nanodispersions, nanosuspensions, polymeric and non-polymeric nanoparticles, polymeric micelles, and other self-assembled structures such as dendrimers and liposomes. Further, Zhang et $\mathrm{al}^{22}$ have reviewed polymeric nanoparticle DDSs, including solid lipid nanoparticles, dendrimers, and liposomes, for antimicrobial drugs. Their review is focused on recent advancements in nanocarriers designed for the delivery of antimicrobial agents. Pandey and Khuller $^{23}$ reviewed anti-TB drug carrying systems designed for pulmonary uses and have thoroughly reviewed the application of liposome-encapsulated anti-TB drugs,

Table 2 Side effects of first-line antituberculosis drugs

\begin{tabular}{|c|c|c|}
\hline Drug & Major adverse effects & Rare adverse effects \\
\hline Isoniazid & Peripheral neuropathy, skin rash, hepatitis, sleepiness and lethargy & Convulsions, psychosis, arthralgia, anemia \\
\hline Rifampin & $\begin{array}{l}\text { Gastrointestinal abdominal pain, nausea, vomiting, hepatitis, } \\
\text { generalized cutaneous reactions, thrombocytopenic purpura }\end{array}$ & $\begin{array}{l}\text { Osteomalacia, pseudo-membranous colitis, pseudo-adrenal } \\
\text { crisis, severe renal stoppage, hemolytic blood paucity }\end{array}$ \\
\hline Pyrazinamide & $\begin{array}{l}\text { Arthralgia, hepatitis, gastrointestinal problems, eg, stomach upset, } \\
\text { nausea, poor appetite and abdominal pain }\end{array}$ & Cutaneous reaction, sideroblastic anemia \\
\hline Streptomycin & $\begin{array}{l}\text { Vestibular and auditory nerve damage renal breakage, cutaneous } \\
\text { allergic reaction }\end{array}$ & $\begin{array}{l}\text { Pain, rash at injection site, numbness around the mouth } \\
\text { and tingling soon after the injection }\end{array}$ \\
\hline Thiacetazone & Skin rash that sometimes has mucosal involvement & Acute hepatic failure, exfoliative dermatitis \\
\hline
\end{tabular}

Reproduced with permission of the European Respiratory Society. Breathe. 2005;2:69-73. ${ }^{18}$ 
Table 3 Side effects of second-line antituberculosis drugs

\begin{tabular}{|c|c|c|}
\hline Drug & Major adverse effects & Rare adverse effects \\
\hline Kanamycin & Vestibular (vertigo) and auditory nerve damage & Cutaneous hypersensitivity \\
\hline Amikacin & Vestibular damage (vertigo) and auditory nerve damage & Clinical renal failure \\
\hline Capreomycin & Nephrotoxicity & \\
\hline $\begin{array}{l}\text { Ethionamide } \\
\text { (prothionamide) }\end{array}$ & $\begin{array}{l}\text { Gastrointestinal anorexia, nausea, diarrhea, abdominal pain, } \\
\text { hepatotoxicity }\end{array}$ & $\begin{array}{l}\text { Convulsions, mental symptoms, impotence, } \\
\text { gynecomastia }\end{array}$ \\
\hline Fluoroquinolones & Gastrointestinal anorexia, nausea, vomiting & $\begin{array}{l}\text { Anxiety, dizziness, headache, convulsions, } \\
\text { rupture of the Achilles tendon }\end{array}$ \\
\hline Cycloserine & Dizziness, headache, depression, psychosis, convulsions & Suicide, generalized hypersensitivity, hepatitis \\
\hline $\begin{array}{l}\text { Para-aminosalicylic } \\
\text { acid }\end{array}$ & $\begin{array}{l}\text { Gastrointestinal anorexia, nausea, vomiting, hypersensitivity } \\
\text { reactions (fever, rash, pruritus) }\end{array}$ & Hypothyroidism, hematological reactions \\
\hline
\end{tabular}

Reproduced with permission of the European Respiratory Society. Breathe. 2005;2:69-73. ${ }^{18}$

microparticles, and nanoparticles in the chemotherapy of pulmonary tuberculosis.

\section{DDSs for pulmonary tuberculosis chemotherapy}

Inhalation has received widespread recognition, as it is a simple, reproducible, and easy to use drug-delivery method. The lung tissues can be easily targeted by making use of the respiratory system. However, the slow release of medicine after respiration remains to be achieved, largely because of the dearth of appropriate equipment specially designed to deliver medicines to the lungs. ${ }^{23}$

The majority of earlier research was focused on polymeric DDSs, especially those involving poly lactic-co-glycolic acid (PLGA) because it is readily available and safe. However, PLGA has limitations for use in the lungs. First, the drugs are released quickly and the remaining polymer takes weeks or months to degrade. ${ }^{24}$ This results in an unwanted aggregation of polymer in the lungs with repeated doses. Secondly, the breakdown of PLGA microspheres causes an acidic hub that spoils $\mathrm{pH}$-susceptible medicines, especially peptides and proteins. ${ }^{25}$ In contrast, surface-corroding polymers, such as poly anhydrides, would not lower the $\mathrm{pH}$, as their degraded fragments do not aggregate because of their high diffusion rates. ${ }^{26,27}$ Thirdly, although PLGA microspheres have a hydrophobic face that causes better particle delivery deeper into the lungs due to agglomeration of the microspheres by weak inter-particle forces; the hydrophobicity of the PLGA surfaces causes protein adsorption that results in quick removal from the alveolar phagocytic cells. ${ }^{28}$

In short, the application of polymeric systems for the sustained and targeted release of drugs in lungs is still at a nascent stage. Scientists have yet to design polymeric systems particularly for pulmonary use and they must overcome the limitations associated with the presently existing polymers, for example, PLGA.

\section{DDSs for the targeted and slow delivery of anti-TB drugs}

Many DDSs have been designed for the targeted and slow delivery of anti-TB drugs by adopting variety of different approaches. Some of these are discussed here.

\section{Inhalable large porous particles (LPPs) of capreomycin}

An MDR-TB patient's treatment may last up to 2 years because the bacteria have developed resistance to two of the most widely prescribed medicines, rifampin and isoniazid. Furthermore, for MDR-TB, other medicines are required and patients have to bear the extra burden of parental injection, mostly of capreomycin. The expected benefits of a simpler pulmonary delivery method are the elimination of administration by injection and improvement of patient compliance.

Figure 3 shows the molecular structure of capreomycin. The capreomycin molecule consists of four active dynamic groups that are potentially active against microbes and the drug is known to be effective in combination with other suitable TB medicines for the elimination of MDR-TB from the lungs. However, much pain is associated with drugs given by injection, along with side effects such as thirst, anorexia, anemia, and, especially, nephrotoxicity, hearing damage, and vestibular splitting of cranial nerve VIII..$^{28-30}$

The normal dosage of capreomycin is $20 \mathrm{mg} / \mathrm{kg}$ of body weight/day (total dose, $1 \mathrm{~g}$ ) for 2-4 months. The dose is injected intramuscularly, which is a major challenge to the administration of the drug for the specified time. ${ }^{31}$ Although capreomycin is effective in MDR-TB, the adverse effects of the drug limit its therapeutic benefits. Targeted 


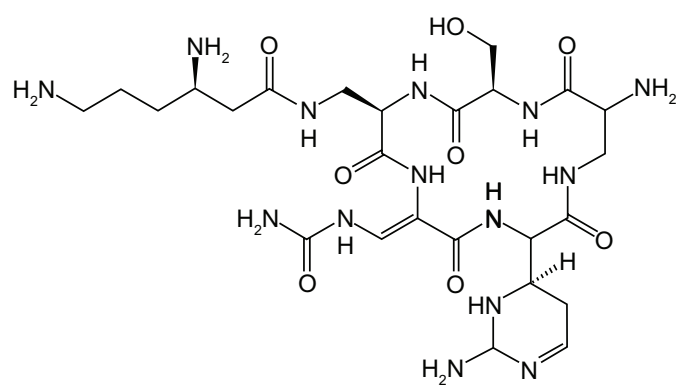

Figure 3 Structure of capreomycin.

drug delivery can potentially sustain its remedial properties while diminishing exposure of the drug to healthy tissues, eliminating the possible adverse effects. ${ }^{31}$

The utilization of aerosolized rifampin-PLGA microparticles in the chemotherapy of lungs TB has already been studied. ${ }^{32-34}$ Low-thickness powders such as LPPs can be aerosolized, allowing the efficient delivery of medicine by simple inhalers. However, while LPPs are recognized for their powerful use in aerosolization, they neither aggregate quickly nor diffuse easily. LPPs also possess lower water solubility, which results in the discharge of drugs into the lungs for extended periods, since their large size inhibits macrophage phagocytes. ${ }^{35,36}$

Garcia-Contreras et $\mathrm{al}^{38}$ designed low-density porous capreomycin sulfate particulates for efficient delivery in lungs with increased bioavailability and the same ability to reduce the TB count in lungs as that accomplished with injection. The pharmacokinetic factors after the administration of capreomycin particles in lungs were established. Garcia-Contreras and Hickey assayed the usefulness of these particles in a small-aerosol inoculum TB model in guinea pig, establishing that capreomycin particles had no undesirable effects. ${ }^{37}$ Garcia-Contreras and Hickey's study reveals that treatment of TB by respiration of capreomycin particles has no side effects and hence is safe to use and effective. ${ }^{37}$ Figure 4 shows a scanning electron microscope image of capreomycin dry powder.

\section{Inhalable rifampin-containing mannitol microparticles}

Mannitol, $\left(\mathrm{C}_{6} \mathrm{H}_{8}(\mathrm{OH})_{6}\right)$, is extracted from the flowering ash plant, called "manna" after its resemblance to the Biblical food. ${ }^{38}$ Mizoe et al ${ }^{39}$ successfully prepared respirable rifampin (RFP)-mannitol (MAN) microparticles using a four-fluidnozzle spray drier. They found that RFP-MAN microparticles were effective in pro-releasing RFP in the lungs. However, RFP is quickly eliminated from the lungs into the blood. The

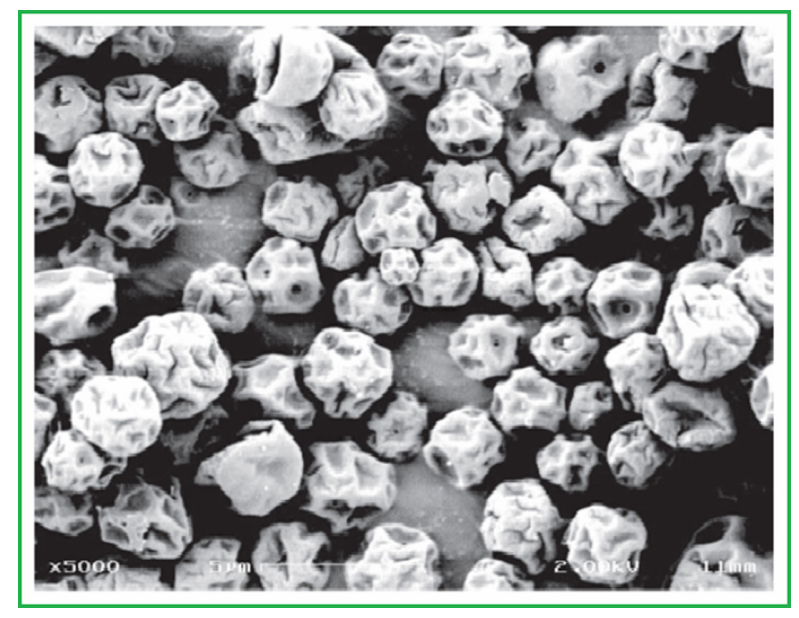

Figure 4 Scanning electron micrograph of spray-dried capreomycin dry powder. Note: Scale bar $=5 \mu \mathrm{m}$.

Garcia-Contreras L, Fiegel J, Telko MJ, et al. Inhaled large porous particles of capreomycin for treatment of tuberculosis in a guinea pig model. Antimicrob Agents Chemother. 2007;5I(8):2830-2836. Reproduced with permission from American Society for Microbiology. ${ }^{38}$

authors' believe that the particles formed by the combination of mannitol and rifampin represent an improved delivery system and note that their method of preparation is easy. However, further research on such DDSs that target alveolar macrophages for the sustained release of RFP and other drugs is required. ${ }^{39}$

\section{Inhalable microparticles of polylactic acid}

Preparation of a biodegradable poly (D-L-lactic acid) microparticle DDS and the successful encapsulation of two important anti-TB drugs, isoniazid and rifampin, have been reported by Sharma et $\mathrm{al}^{40}{ }^{40}$ When the prepared microparticles were introduced in the lungs, they were phagocytized rapidly by alveolar macrophages - the respirable microparticles were taken in by the cultured macrophages. However, it has been found that a greater number of microparticles can be utilized to transport the medicine in a bronchopulmonary system by the 2-minute introduction of fluidized material. The amounts of soluble medicines administered by intravascular transportation were found to be less than those of respirable material. ${ }^{41}$

Inhalable microparticles containing multiple anti-TB drugs would result in the reduction of dose and dosing frequency that would ultimately result in the reduction of toxicity and direct targeting of Mycobacterium spp. in macrophages. Dry powder inhalation formulations have been developed for breathing problems and for the transportation of various agents deep into the lungs. ${ }^{28,41,42}$ Though phagocytosis and sequestration of respirable fine particles may be a problem in drug release to other cells, this is not of concern in lung 
tissues and, in fact, are beneficial in eliminating the TB. Phagocytized microlevel particulates are probably able to transport a greater quantity of medicine to the lungs than orally administered medicines. Additionally, microparticles can reduce the need for repetitive administration and decrease the therapeutic concentration of drug required. Further, they are beneficial in sustaining drug release and in enhancing patient comfort. Therefore, encapsulation of multiple drugs in respirable material would be of great advantage in TB chemotherapy, as single-drug therapy of TB is not favored due to the greater chance of drug-resistant TB. ${ }^{43}$

Poly-L-lactic acid has also been utilized as an anti-TB DDS. ${ }^{41}$ Microparticles containing higher concentrations of two anti-TB drugs were evaluated for their suitability as a dry respirable powder targeting alveolar macrophages. The formulation of the prepared solution was 1:2 of rifampin and isoniazid to poly-L-lactic acid. Microparticles taken in via breathing can incorporate a greater amount of drug. Designed respirable microparticles tend to target the alveolar macrophages rather than lung epithelium, which may result in the sustained discharge of drug in the interior part of classical or maturation-captivated phagosomes over several days. Further research needs to be undertaken on microparticle habitation and biodegradation in in vivo analysis. The amount of drug has been found to be 20 times greater when microparticles are inhaled rather than taken in solution. Hence, microparticles may be a better option for the targeted delivery of drugs to lung macrophages. ${ }^{28}$

\section{Tuneable systems for the controlled release of drugs into the lungs}

Inhalation is gaining recognition as a practical, noninvasive, and simple method of drug delivery to the lung tissues and/or systemic circulation. However, the issue of continual drug discharge after inhalation is still in the early stages of research, due to the scarcity of appropriate materials and architecture for targeting the lungs. Fu et al have tried to overcome this hurdle by designing a new family of ether-anhydride copolymers consisting of US Food and Drug Administration (FDA)-permitted monomers, including polyethylene glycol (PEG) and sebacic acid. ${ }^{24}$ PEG $\left(\mathrm{C}_{2 \mathrm{n}} \mathrm{H}_{4 \mathrm{n}}+2 \mathrm{O}_{\mathrm{n}+1}\right)$ is a polyether compound with numerous applications in areas ranging from industrial manufacturing to medicine. It has also been identified as polyethylene oxide or polyoxyethylene, according to its molecular weight. Sebacic acid is a naturally occurring dicarboxylic acid with the composition (HOOC) $\left(\mathrm{CH}_{2}\right)_{8}(\mathrm{COOH})$. In its pure form, it is a white flake or powdered crystal.
Hydrophobic monomers can be copolymerized with PEG to form novel materials with exceptional ability in controlling drug release in an aqueous atmosphere. Bulky absorbent particles have been prepared with these new polymers by exploiting key composites to design particles with much better physical characteristics for drug delivery deep into the lungs. ${ }^{23}$ Sebacic acid is approved by the US FDA for human brain tumor treatment, while PEG is accepted for a number of applications in medical science. The established efficacy of sebacic acid and PEG in healthy tissues should encourage their endorsement for use in lung treatments. Poly(esteranhydride)s have noticeably variable degradation periods, from hours to many days, according to their formulations, hence would be more appropriate for drug delivery in lungs than current polymers such as PLGA. ${ }^{24}$

Fu et al have reported a new family of PEG-based poly(ether-anhydride)s designed to overcome many of the disadvantages associated with PLGA. They designed a particle with physical features appropriate for transporting drugs to the different areas of the lungs. Continued advances in the fabrication of particle formulation, particle elucidation techniques, and in host-guest approaches should enhance the chances of the future advancement of appropriate polymeric vehicles for sustained drug delivery in the lungs. These kinds of systems will endeavor to find applications in both local remedies (with the lung as target) and systemic treatments (delivery to the blood). Fu et al's study demonstrates that poly anhydrides of molecular weights $>10 \mathrm{KDa}$ are suitable for efficient manufacturing of microparticles that can target lungs and deliver drugs in a sustained manner. ${ }^{24}$

\section{Glucan particles (GPs) as a targeted delivery system to macrophages}

GPs are 2-4 $\mu \mathrm{m}$ round, empty, spongy shells isolated from the baker's yeast Saccharomyces cerevisiae. The surface of GPs consists mainly of 1,3- $\beta$-glucan. These particles are easily phagocytized via receptor-mediated cell uptake by macrophages, wherein phagocytic cells communicate with glucan receptors. ${ }^{44}$

The use of GPs for delivery of macromolecules, such as DNA, siRNA, and proteins, has been successfully established both in vitro and in vivo. ${ }^{45,46}$ Soto et al have successfully encapsulated the TB antibiotic rifampin in glucan particles by making use of an alginate or chitosan hydrogel to close the GP pores and prolong the drug release. ${ }^{44}$ The void holes of the GPs permit the efficient absorption and encapsulation of drugs. They have reported the sustained release for periods of 24-72 hours in vitro and have found 
that the formulation diminishes the intracellular TB count in infected bone marrow-derived macrophages. The decline in colony-forming units in the infected macrophages at sub-minimum inhibitory concentration levels of antibiotic demonstrates the significance of the targeted rifampin release and potentially lessens adverse affects on healthy tissues. The amount of rifampin released in the GP formulations was below the free rifampin minimal inhibitory concentration, demonstrating that GP-targeted rifampin delivery to macrophages improves rifampin's therapeutic effects. ${ }^{44}$ Figure 5 shows microscopic images of empty GPs and GP-rifampin samples.

\section{Plant proteins as DDSs}

Zein, one of the best regarded plant proteins, is a soft, yellow crush of corn proteins with diverse industrial and food applications ${ }^{47,48}$ (see Figure 6). Traditionally, zein has been utilized in the production of a wide range of industrial products, such as, in paper cup coatings, soda bottle cap linings, fabric buttons for clothing, adhesives, and binders. ${ }^{49}$

Among the different options explored, polymeric microscaled material is receiving much attention for the controlled delivery of remedially potent agents. Microparticulate systems can be formed in a variety of ways by utilizing physicochemical methods - for example, solvent evaporation and phase separation - or mechanical procedures - such as, spray drying and cold precipitation. ${ }^{73}$ The solvent departure procedure is known for its use in the design of microspheres,

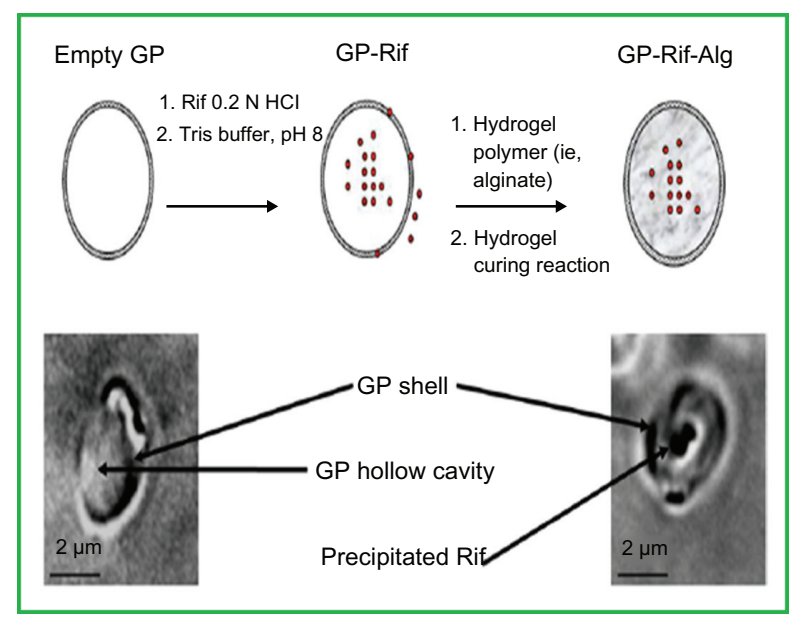

Figure 5 Top: Schematic representation of rifampin (Rif) (red circles) loaded into glucan particles (GPs) and sealed with a hydrogel. Bottom: bright-field microscope images of an empty GP (left) and a GP-Rif sample (right).

Reproduced from Soto E, Kim YS, Lee J, Kornfeld H, Ostroff G. Glucan particle encapsulated rifampicin for targeted delivery to macrophages. Polymers. 2010; 2(4):68I-689. ${ }^{44}$

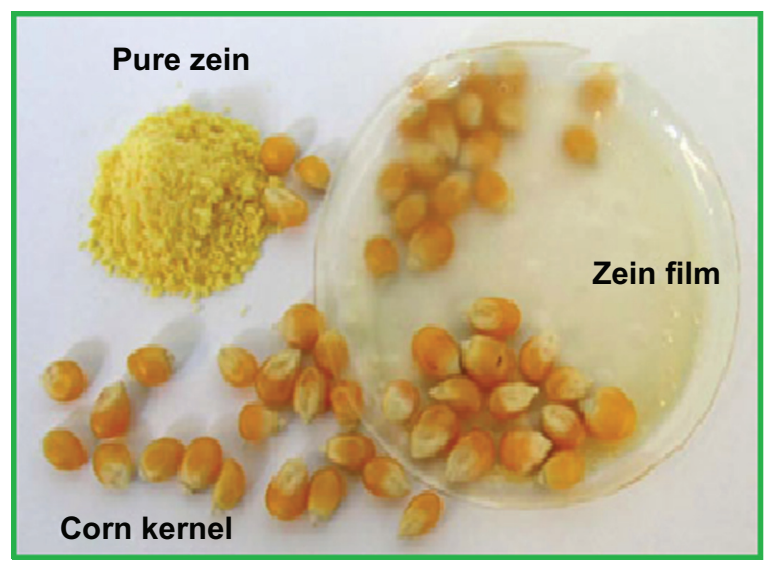

Figure 6 Different forms of zein.

Global Protein Products, Inc. Zein: a natural biopolymer from a renewable resource [web page on the Internet]. Fairfield, ME: Global Protein Products, Inc; 201I. Available from: http://www.globalprotein.com/zein.html. Reproduced with permission from Global Protein Products Inc. ${ }^{71}$

as it is simple, reproducible, and can be processed rapidly with a minimum of controllable process variables that can be easily applied. ${ }^{49,50}$

Mehta et al have successfully designed stable microspheres with first-line anti-TB medicines. Rifampin, isoniazid, and pyrazinamide were encapsulated into plant proteins and their sustained delivery was evaluated. The use of plant-protein microspheres for single and multiple drug formulations is an example of a DDS being used to better manage TB drugs. The stability and discharge profiles of first-line anti-TB drugs encapsulated in the microspheres may result in much better management of tuberculosis. ${ }^{51}$

\section{Gelatin nano-vehicles}

Gelatin is a combination of peptides and proteins formed by the partial hydrolysis of collagen. The natural molecular bonds between each of the collagen threads degrade into a shape that is easily reshuffled. Gelatin liquefies on heating and solidifies again upon cooling. It forms a viscous solution with water that is converted to gel upon cooling. Its composition is similar in many ways to its parent, collagen. ${ }^{52}$

Various polymeric nanoparticle systems have been designed keeping green chemistry in mind, such as alginate, poly lactide-co-glycolide, and chitosan for the encapsulation of anti-TB drugs and have been evaluated for targeted and slow release. Gelatin nanoparticles offer several advantages for use as DDSs, such as biodegradability, biocompatibility, low antigenicity, cost effectiveness, several active sites for fastening the desired compounds, and easier utilization in parenteral forms. ${ }^{53-55}$

Successful formation of nano-scaled gelatin particles by a simple desolvation process of entrapment of the rifampin has 
been reported by Saraogi et al. ${ }^{56}$ In their study, round gelatin nanoparticles of around $264 \mathrm{~nm}$ with a low polydispersity index were obtained. The gelatin nanoparticles demonstrated controlled release for up to 72 hours, signifying their possible benefit in sustained delivery formulation. ${ }^{56}$ In addition, the formulated system was less cytotoxic and had improved bioavailability and drug release into the lung tissue.

Additionally, gelatin nanoparticle-based chemotherapy has much better therapeutic efficacy compared with common chemotherapy. It was also found that gelatin-encapsulated rifampin results in a major decrease in bacteria count in the lungs and spleen in TB-induced mice. Gelatin nanoparticles possess significant targetability and the reduction in dosage possibly diminishes side effects and results in improved tuberculosis treatment. ${ }^{56}$ Thus, it could be envisaged that gelatin nanoparticles can be exploited as a DDS for the controlled release of drugs for lung tissues, resulting in the reduction of adverse effects and improved remedial effects of the prescribed medicines. ${ }^{56,57}$

\section{Chitosan-montmorillonite (MMT) hydrogel}

Hua et al has reported MMT as an additional matrix for chitosan beads that, in comparison to pure chitosan beads, results in much improved entrapment of drugs, increased swelling, and controlled release of drugs from the chitosan hydrogel beads. ${ }^{58}$ The inter-particle force of magnetism between chitosan and MMT enhances the strength of the beads, which indicates them to be an excellent prospective drug-delivery vehicle for controlling drug release. Further, a controlled-release system could be formed by introducing MMT into the beads of a nanocomposite. Hua et al prepared a series of ofloxacin/MMT/chitosan hydrogels with the application of solution encapsulation and ionic cross-linking with sodium tripolyphosphate. ${ }^{58}$ They found that beads showed improved drug encapsulation and sustained release. Such features greatly depend on the MMT. The breakdown of pure chitosan beads at pH 1.2 was surmounted by the addition of MMT; this modification of the system resulted in much improved targetability at low $\mathrm{pH}$. MMT has high specific surface area and displays improved adsorptibility with ion exchange capability, thus is therefore suitable as a drug transportation vector.

The encapsulation or intercalation of organic substances into inorganic layered two-dimensional solids can be exploited for the synthesis of organic-inorganic nanohybrids with the characteristics of the inorganic host and organic guest within one material, as reported by Mohanambe et al. ${ }^{59}$ MMT itself has also been used as a DDS for timolol maleate.
Joshi et al successfully encapsulated timolol maleate in MMT and also studied its in vitro release. ${ }^{73}$ Akyuz successfully intercalated isoniazid within MMT and saponite. ${ }^{60}$ They found that the entrapment efficiency of the beads improved upon the addition of MMT. Furthermore, they reported that the encapsulation of ofloxacin in beads in the absence of MMT was $31.2 \%$, while the analogous encapsulation in the beads with MMT added varied from $45.3 \%$ to $83.5 \%$. Thus, the introduction of MMT very efficiently enhances the entrapment of ofloxacin. ${ }^{60}$ This encourages application of this strategy and new strategies to improve encapsulation and controlled drug release should be investigated.

Organic-inorganic nanohybrids are receiving increasing attention as possible DDSs. Hussein et al recently reported a nanohybrid of the anticancer drugs ellagic acid and zinclayered hydroxide. ${ }^{61}$ The formation of an organic-inorganic nanohybrid can be achieved in a variety of ways and such method development is a very attractive area in the field of nanomedicine. Recently, Hussein Al Ali et al reported a novel and simple method for the preparation of a zinc-layered organic nanohybrid for drug delivery. ${ }^{62}$

\section{Nanocomposite hydrogels of polyvinyl alcohol: sepiolite}

According to the US FDA's Biopharmaceutics Classification System, rifampin is a class II drug (low solubility and high permeability) that is infamous for its poor solubility in water and bioavailability issues. ${ }^{63}$ To improve the dissolution and bioavailability of hydrophobic compounds such as rifampin, numerous procedures have been introduced, including reducing the particle size and the crystallinity of the medicine and/or applying a transportation agent with a high specific surface area. The deposition of such medicines onto carriers with high surface areas is the best approach for altering the solubility features of rifampin. It is well known that inorganic species can be utilized to advance the solubility kinetics of drugs. For example, Monkhouse and Lach reported the use of silica for the enhancement of the dissolution kinetics of various drugs including chloramphenicol, aspirin, and indomethacin. ${ }^{64}$

Sepiolite is a composite of magnesium silicate with the empirical formula $\mathrm{Mg}_{4} \mathrm{Si}_{6} \mathrm{O}_{15-}(\mathrm{OH})_{2} \cdot 6 \mathrm{H}_{2} \mathrm{O}$. It can be found in a fibrous or fine-particulate state. The name is derived from a supposed resemblance to the material of the spongy bones of the cuttlefish from the Greek word "sepion." As it can float on the water, for this reason its German name is "meerschaum," meaning sea foam. ${ }^{65}$

Viçosa et al designed nanocomposite hydrogels based on polyvinyl alcohol and sepiolite and evaluated their application 
as drug-delivery vehicles by taking rifampin as a model drug. ${ }^{66}$ They found that both rifampin and sepiolite resulted in significant alteration in the microstructure of the polyvinyl alcohol matrix, resulting a change in the characteristics of swelling and diffusion. Akyuz and Akyuz reported the entrapment of pyrazinamide and 4-aminopyrimidine within natural and ion-exchanged MMT. Pyrazinamide and 4-aminopyrimidine intermingled with MMT by direct or indirect coordination through water molecules with the substitutable cations. ${ }^{60,65}$

\section{Bioceramic systems for osteoarticular tuberculosis: porous beta-tricalcium phosphate}

Osteoarticular tuberculosis is a persistent inflammatory form of the TB that affects joints. It arrives at the skeleton and joints by hematogenous spread. ${ }^{67}$ Worldwide, osteoarticular tuberculosis accounts for approximately $10 \%-11 \%$ of extrapulmonary TB cases; that is, about 19-38 million cases annually. ${ }^{44-48}$ According to WHO, spinal tuberculosis is a cruel form of extrapulmonary tuberculosis and is allocated to category I. According to WHO standards, all cases of spine TB should be treated for at least 6 months. ${ }^{74}$ However, several specialists in India (an endemic place of disease) choose to continue treatment until there is satisfactory radiological evidence of complete elimination of bacteria, thus treatment can last for $1-1.5$ years. ${ }^{67}$ In osteoarticular tuberculosis, the osseous focal point escalated by TB results in poor blood supply and it is not easy for blood carrying anti-TB drugs to reach the focus. Hence, any tuberculosis bacteria existing at the osseous focal point or which survive after the removal of the infected tissues by operation are hard to entirely eliminate with standard methods of treatment; any such remaining bacteria can easily turn into dormant bacillus and will replicate quickly once in a comorbid environment. ${ }^{68}$

Another general regulation in the area of osteoarticular tuberculosis treatment has been surgical involvement. ${ }^{69,70}$ Due to advancements in fixation equipment and technology, surgery on the bone disease foci is recommended. ${ }^{44}$ However, a course of multiple drugs is still regrettably obligatory in addition to surgery. The contemporary course of therapy for curing osteoarticular tuberculosis was a 7-28-day preoperative and a postoperative 6-9 month course of multiple anti-TB medicines to strengthen the therapeutic results.

To limit or even avoid having to initiate chemotherapy after debridement and reduce lesion to hepatic and renal functions, orthopedic consultants are more inclined towards the use of sustained drug-discharge systems, which offer additional effectual and complimentary procedures to improve drug delivery to desired places. ${ }^{14,68-70}$ As already noted, PLGA has received attention as a foundation component of microparticles for anti-TB drug delivery into the lungs. However, the acidification of degrading PLGA microspheres entrenched in the cavities of defective bone may provoke a considerable lowering of $\mathrm{pH},{ }^{59,60,68}$ which could result in drug-resistant TB.

Permeable beta-tricalcium phosphate $(\beta$-TCP) bioceramics are among the bone-tissue manufacturing scaffolds considered acceptable for use in recovering any remaining empty portions of bone. An implantable antitubercular amalgamated scaffold DDS with mesoporous silica nanoparticles and bioactive glass coated in a $\beta$-TCP bioceramic as temporary holding material was fabricated by Zhu et al. ${ }^{68}$ The complex system was reported to show greater rifampin and isoniazid encapsulation capability than a pure $\beta$-TCP scaffold. In comparison to the complete in vitro release of all drugs in 72 hours from a pure $\beta$-TCP scaffold, this composite-scaffold DDS (CS-DDS) astonishingly demonstrated the controlled co-discharge of isoniazid and rifampin for over a month. The mesostructure of nanoparticles and the cover of bioactive glass and/ or hydroxyl apatite deposits that appeared at some stage during the release time played vital functions in extraordinarily prolonging the drugs' release in both in vitro and in vivo analysis. The therapeutic quantity of both isoniazid and rifampin for treating TB in vivo can be sustained for an extended period over 6 weeks with no major long-term lesions to the liver and kidneys. ${ }^{68}$

This kind of approach suggests future innovative uses for the material, containing antibacterial agents, used for temporary holding, which can release drugs over a long period. It has potential not only in the treatment of TB but also when tailored for application in bone replacement surgeries to avoid internal infection and post-surgery complications.

\section{Advantages of DDSs in tuberculosis chemotherapy}

Anti-TB drugs administered in traditional ways interact with healthy tissues before reaching the desired site requiring treatment, and thus harm healthy tissues because these tissues are exposed to the drugs for a longer period. DDSs do not allow unrelated sites to be exposed and deliver the drugs to the target place. Traditional treatment of TB involves patients having to take a large number of pills, up to eight at 
one time, for 3-24 months and, in case of MDR-TB, patients also have to have an intramuscular injection (eg, kanamycin, capreomycin, and amikacin).

Although the development of novel anti-TB drugs remains the prime priority, development of DDSs with targeted and controlled-release properties has many potential benefits. Patient noncompliance, the most common reason for treatment failure, can be circumvented by the tendency of a delivery system to release the drug in a sustained manner. DDSs not only reduce dosing frequency but also the side effects related to second-line TB medicines and drug degradation. Furthermore, drug-delivery vehicles may be able to manage the strongest therapeutic effect of the drugs at their lower concentrations, as reported by Soto et al. ${ }^{44}$ Most importantly, such developed drug-delivery vehicles could also be utilized for new anti-TB drugs as they become available, to treat latent and active bacteria, curtailing the course of chemotherapy.

Inhaled chemotherapy may be more advantageous for the patients with pulmonary tuberculosis.
Biocompatible drug-delivery vehicles have been designed with particle sizes that can be safely phagocytized.

As MDR-TB cannot be effectively treated with most firstline TB antibiotics, matters are complicated because more side effects are associated with second-line anti-TB drugs. However, this can be overcome with drug-delivery vehicles that are able to deliver the drugs to desired places without cytotoxic effects on healthy tissues.

DDSs could also be used to solve the water solubility issues related to anti-TB drugs, such as rifampin, which is infamous for its poor water solubility. Encapsulation and/or loading efficiency can also be enhanced by the adoption of various strategies. Zeta potential, the surface charge of material, can be varied using different methods and is a key factor to investigate in the delivery of drugs to the desired cells and tissues. In designing DDSs, researchers need to overcome the flaws associated with previously engineered DDSs.

The advantages and disadvantages of different DDSs are summarized in Table 4.

Table 4 Advantages and disadvantages of different drug-delivery systems

\begin{tabular}{|c|c|c|}
\hline Drug-delivery system & Advantages & Disadvantages/suggestions \\
\hline Large porous particles of capreomycin & $\begin{array}{l}\text { Elimination of injection, reduces the side effects of drugs, } \\
\text { biodegradable, increased bioavailability, controlled } \\
\text { release of drug }{ }^{24}\end{array}$ & - \\
\hline $\begin{array}{l}\text { Microparticles of rifampin-containing } \\
\text { mannitol }\end{array}$ & $\begin{array}{l}\text { Easy to prepare, targeted, and effective; pro-release } \\
\text { of the drug into the lungs }{ }^{58}\end{array}$ & Uncontrolled release of drug ${ }^{58}$ \\
\hline Microparticles of poly (D-L-lactic acid) & $\begin{array}{l}\text { Direct delivery to the lungs and microparticles } \\
\text { phagocytized rapidly by alveolar macrophages; multiple } \\
\text { drug encapsulation, maintaining a higher drug concentration } \\
\text { than the drug given by intravascular means }{ }^{28,42}\end{array}$ & In vivo analysis needs to be done \\
\hline $\begin{array}{l}\text { Tunable systems for controlled } \\
\text { release into the lungs }\end{array}$ & $\begin{array}{l}\text { Monomers are already in medical application, controlled } \\
\text { release of drugs, can be tuned to target side of interest }{ }^{23}\end{array}$ & - \\
\hline $\begin{array}{l}\text { Targeted delivery of glucan particles } \\
\text { to macrophages }\end{array}$ & $\begin{array}{l}\text { Glucan particles are easily taken in by macrophages, } \\
\text { controlled release of drug, and good targetability; } \\
\text { therapeutic effect can be maintained with a lower } \\
\text { concentration than the minimum inhibitory concentration; } \\
\text { reduces adverse effects of rifampin, such as hepatotoxicity }\end{array}$ & $\begin{array}{l}\text { Encapsulated amount of drug was below } \\
\text { the minimum inhibitory concentration and } \\
\text { glucan-chitosan particles dissolve at } \mathrm{pH} 5 \\
\text { and result in quick drug release }{ }^{33}\end{array}$ \\
\hline Plant proteins: zein & Multiple drug encapsulation and safe to use $\mathrm{e}^{51}$ & Sustained release needs to be improved \\
\hline Gelatin nano-vehicles & $\begin{array}{l}\text { Biocompatible, biodegradable, low antigenicity, low cost, } \\
\text { numerous available active groups for attaching targeting } \\
\text { molecules, uniform distribution of the particles, extended } \\
\text { controlled release, nontoxic compared with free drug, } \\
\text { improved pharmacokinetics, have the potential to reduce } \\
\text { dosing frequency }{ }^{53-55}\end{array}$ & - \\
\hline Chitosan-montmorillonite hydrogel & $\begin{array}{l}\text { Good targetability and controlled release at lower } \mathrm{pH} \text {; } \\
\text { improved encapsulation properties }\end{array}$ & $\begin{array}{l}\text { In vitro and in vivo analysis for the } \\
\text { evaluation of the therapeutic effect and } \\
\text { cytotoxicity needs to be done }\end{array}$ \\
\hline $\begin{array}{l}\text { Nanocomposite hydrogels of poly } \\
\text { (vinyl alcohol) and sepiolite }\end{array}$ & $\begin{array}{l}\text { Improves the water solubility of drugs, especially that } \\
\text { of rifampin }{ }^{64}\end{array}$ & $\begin{array}{l}\text { Swelling behavior and crystallinity of the } \\
\text { hydrogels are not fully understood and } \\
\text { in vitro and in vivo analysis for the evaluation } \\
\text { of therapeutic effect needs to be done }{ }^{64}\end{array}$ \\
\hline
\end{tabular}




\section{Conclusion}

TB still poses a devastating threat to the world and there is an urgent need to develop novel anti-TB drugs. DDSs offer a number of advantages over traditional methods of anti-TB drug administration and, once developed, such DDSs can be utilized for new anti-TB drugs. Some flaws are associated with the current DDSs that need to be overcome and dedication is required to take DDSs from in vitro and in vivo analyses to clinical trials.

\section{Acknowledgment}

Funding for this research was provided by the Higher Education Commission of Malaysia under the Commonwealth Scholarship and Fellowship Plan (Ref: KPT.B.600-6/3, vol 68), for Bullo Saifullah, and Ministry of Science, Technology and Innovation of Malaysia (MOSTI), under National Nanotechnology Directorate, grant No. NND/NA/1)/TD11-010, (UPM Vot No. 5489100).

\section{Disclosure}

The authors report no conflicts of interest in this work.

\section{References}

1. World Health Orgnization (WHO) Report 2011. Global TB control. Available at http://www.who.int/tb/publications/global_report/en/.

2. Russell DG, Barry CE 3rd, Flynn JA. Tuberculosis: what we don't know can, and does, hurt us. Science. 2010;328(5980):852-856.

3. Chan ED, Iseman MD. Multidrug-resistant and extensively drug-resistant tuberculosis: a review. Curr Opin Infect Dis. 2008;21(6):587-595.

4. World Health Organization (WHO).XDR-TB: Extensively Drug-resistant Tuberculosis March 2007. Geneva: WHO; 2007. Available from: http:// www.who.int/entity/tb/challenges/xdr/news_mar07.pdf. Accessed August 1, 2012.

5. Davies PD. Drug resistant tuberculosis. J R Soc Med. Jun 2001;94(6): 261-263.

6. Ryan KJ, Ray CG. Sherris Medical Microbiology: An Introduction to Infectious Diseases. 4th ed. New York, NY: McGraw-Hill; 2004.

7. Ferrari G, Langen H, Naito M, Pieters J. A coat protein on phagosomes involved in the intracellular survival of mycobacteria. Cell. 1999; 97(4):435-447.

8. Meena LS, Rajani. Survival mechanisms of pathogenic Mycobacterium tuberculosis H37Rv. FEBS J. 2010;277(11):2416-2427.

9. Moulder JW. Comparative biology of intracellular parasitism. Microbiol Rev. 1985;49(3):298-337.

10. Gordon AH, Hart PA, Young MR. Ammonia inhibits phagosomeslysosome fusion in macrophages. Nature. 1980;286(5768):79-81.

11. Crowle AJ, Dahl R, Ross E, May MH. Evidence that vesicles containing living, virulent Mycobacterium tuberculosis or Mycobacterium avium in cultured human macrophages are not acidic. Infect Immun. 1991;59(5):1823-1831.

12. Sturgill-Koszycki S, Schlesinger PH, Chakraborty P, et al. Lack of acidification in Mycobacterium phagosomes produced by exclusion of the vesicular proton-ATPase. Science. 1994;263(5147): 678-681.

13. Yuan Y, Lee RE, Besra GS, Belisle JT, Barry CE 3rd. Identification of a gene involved in the biosynthesis of cyclopropanated mycolic acids in Mycobacterium tuberculosis. Proc Natl Acad Sci U S A. 1995;92(14): 6630-6634.
14. Falk R, Randolph TW, Meyer JD, Kelly RM, Manning MC. Controlled release of ionic compounds from poly (L-lactide) microspheres produced by precipitation with a compressed antisolvent. $J$ Control Release. 1997;44(1):77-85.

15. Pandey R, Sharma A, Zahoor A, Sharma S, Khuller GK, Prasad B. Poly (DL-lactide-co-glycolide) nanoparticle-based inhalable sustained drug delivery system for experimental tuberculosis. J Antimicrob Chemother. 2003;52(6):981-986.

16. WHO. Global Tuberculosis Control: Surveillance, Planning, Financing. WHO report WHO/HTM/TB/2005.349. Geneva: WHO; 2005. Available from: http://library.cphs.chula.ac.th/Ebooks/AnnualReport/WHOreport/ WHOREPORT2005.pdf. Accessed August 1, 2012.

17. Fourth annual meeting of the Stop TB Working Group onDOTS-Plus for MDR-TB Paris, France October 27-28, 2003. http://whqlibdoc.who. int/hq/2004/WHO_HTM_TB_2004.341.pdf.

18. Zaleskis R. The side-effects of TB therapy. Breathe. 2005;2(1):5.

19. Prabakaran D, Singh P, Jaganathan K, Vyas SP. Osmotically regulated asymmetric capsular systems for simultaneous sustained delivery of anti-tubercular drugs. J Control Release. 2004;95(2):239-248.

20. Smith JP. Nanoparticle delivery of anti-tuberculosis chemotherapy as a potential mediator against drug-resistant tuberculosis. Yale J Biol Med. 2011;84(4):361-369.

21. Sosnik A, Carcaboso AM, Glisoni RJ, Moretton MA, Chiappetta DA. New old challenges in tuberculosis: potentially effective nanotechnologies in drug delivery. Adv Drug Deliv Rev. 2010;62(4-5): 547-559.

22. Zhang L, Pornpattananangku D, Hu CM, Huang CM. Development of nanoparticles for antimicrobial drug delivery. Curr Med Chem. 2010;17(6):585-594.

23. Pandey R, Khuller G. Antitubercular inhaled therapy: opportunities, progress and challenges. J Antimicrob Chemother. 2005;55(4):430-435.

24. Fu J, Fiegel J, Krauland E, Hanes J. New polymeric carriers for controlled drug delivery following inhalation or injection. Biomaterials. 2002;23(22):4425-4433.

25. Batycky RP, Hanes J, Langer R, Edwards DA. A theoretical model of erosion and macromolecular drug release from biodegrading microspheres. J Pharm Sci. 1997;86(12):1464-1477.

26. Mader K, Gallez B, Liu KJ, Swartz HM. Non-invasive in vivo characterization of release processes in biodegradable polymers by lowfrequency electron paramagnetic resonance spectroscopy. Biomaterials. 1996;17(4):457-461.

27. Shieh L, Tamada J, Chen I, Pang J, Domb A, Langer R. Erosion of a new family of biodegradable polyanhydrides. J Biomed Mater Res. 1994;28(12): 1465-1475.

28. Visser J. Van der Waals and other cohesive forces affecting powder fluidization. Powder Technol. 1989;58(1):1-10.

29. Muttil P, Kaur J, Kumar K, Yadav AB, Sharma R, Misra A. Inhalable microparticles containing large payload of anti-tuberculosis drugs. Eur J Pharm Sci. 2007;32(2):140-150.

30. Donomae I. Capreomycin in the treatment of pulmonary tuberculosis. Ann N Y Acad Sci. 1966;135(2):1011-1038.

31. Garfield JW, Jones JM, Cohen NL, Daly JF, McClement JH. The auditory, vestibular and renal effects of capreomycin in humans. Ann NY Acad Sci. 1966;135(2):1039-1046.

32. Brown J, Dooley D, Backer H. Drug-Resistant Tuberculosis: A Survival Guide for Clinicians. 1st ed. San Francisco, CA: Tuberculosis Reference Centre, California Department of Health Services, and Francis J Curry National Tuberculosis Centre; 2004.

33. O'Hara P, Hickey AJ. Respirable PLGA microspheres containing rifampicin for the treatment of tuberculosis: manufacture and characterization. Pharm Res. 2000;17(8):955-961.

34. Suarez S, O'Hara P, Kazantseva M, et al. Airways delivery of rifampicin microparticles for the treatment of tuberculosis. J Antimicrob Chemother. 2001;48(3):431-434.

35. Suarez S, O'Hara P, Kazantseva M, et al. Respirable PLGA microspheres containing rifampicin for the treatment of tuberculosis: screening in an infectious disease model. Pharm Res. 2001;18(9):1315-1319. 
36. Edwards DA, Hanes J, Caponetti G, et al. Large porous particles for pulmonary drug delivery. Science. 1997;276(5320):1868-1871.

37. Garcia-Contreras L, Hickey AJ. Pharmacokinetics of aerosolized rifampicin in the guinea pig. In: Dalby RN, Byron PR, Peart J, Farr SJ, editors. Respiratory Drug Delivery VIII. Vol 2. Raleigh, NC: Davis Horwood International Publishing; 2002:699-702.

38. Garcia-Contreras L, Fiegel J, Telko MJ, et al. Inhaled large porous particles of capreomycin for treatment of tuberculosis in a guinea pig model. Antimicrob Agents Chemother. 2007;51(8):2830-2836.

39. Mizoe T, Ozeki T, Okada H. Application of a four-fluid nozzle spray drier to prepare inhalable rifampicin-containing mannitol microparticles. AAPS Pharm Sci Tech. 2008;9(3):755-761.

40. Sharma R, Saxena D, Dwivedi AK, Misra A. Inhalable microparticles containing drug combinations to target alveolar macrophages for treatment of pulmonary tuberculosis. Pharm Res. 2001;18(10):1405-1410.

41. Kawashima Y, Serigano T, Hino T, Yamamoto H, Takeuchi H. Surface-modified antiasthmatic dry powder aerosols inhaled intratracheally reduce the pharmacologically effective dose. Pharm Res. 1998;15(11):1753-1759.

42. Malcolmson RJ, Embleton JK. Dry powder formulations for pulmonary delivery. Pharm Sci Technol Today. 1998;1:394-398.

43. O'Brien RJ. The treatment of tuberculosis. In: Reichman LB, Hershfield ES, editors. Tuberculosis: A Comprehensive International Approach: New York, NY: Marcel Dekker; 1993:1-20.

44. Soto E, Kim YS, Lee J, Kornfeld H, Ostroff G. Glucan particle encapsulated rifampicin for targeted delivery to macrophages. Polymers. 2010;2(4):681-689.

45. Aoudi M, Tesz GJ, Nicoloro SM et al. Orally delivered siRNA targeting macrophage Map4k4 suppresses systemic inflammation. Nature. 2009, 458:1180-1184.

46. Soto ER, Ostroff GR. Characterization of multilayered nanoparticles encapsulated in yeast cell wall particles for DNA delivery. Bioconjug Chem. 2008;19(4):840-848.

47. Lawton JW. Zein: a history of processing and use. Cereal Chemistry. 2002;79(1):1-18.

48. Benita S, editor. Microencapsulation: Methods and Industrial Applications. New York, NY: Marcel Dekkar; 1996.

49. Kim BK, Hwang SJ, Park JB, Park HJ. Preparation and characterization of drug-loaded polymethacrylate microspheres by an emulsion solvent evaporation method. J Microencapsul. 2002;19(6):811-822.

50. Momany FA, Sessa DJ, Lawton JW, Selling GW, Hamaker SA, Willett JL. Structural characterization of alpha-zein. JAgric Food Chem. 2006;54(2):543-547.

51. Mehta SK, Kaur G, Verma A. Fabrication of plant protein microspheres for encapsulation, stabilization and in vitro release of multiple anti-tuberculosis drugs. Colloids Surf A Physicochem Eng Asp. 2011;375(1-3):219-230.

52. Ward AG. The Science and Technology of Gelatin. New York, NY: Academic Press; 1977

53. Kaur A, Jain S, Tiwary AK. Mannan-coated gelatin nanoparticles for sustained and targeted delivery of didanosine: in vitro and in vivo evaluation. Acta Pharm. 2008;58(1):61-74.

54. Coester CJ, Langer K, van Briesen H, Kreuter J. Gelatin nanoparticles by two step desolvation - a new preparation method, surface modifications and cell uptake. J Microencapsul. 2000;17(2):187-193.

55. Verma AK, Sachin K, Saxena A, Bohidar HB. Release kinetics from bio-polymeric nanoparticles encapsulating protein synthesis inhibitorcycloheximide, for possible therapeutic applications. Curr Pharm Biotechnol. 2005;6(2):121-130.

International Journal of Nanomedicine

\section{Publish your work in this journal}

The International Journal of Nanomedicine is an international, peerreviewed journal focusing on the application of nanotechnology in diagnostics, therapeutics, and drug delivery systems throughout the biomedical field. This journal is indexed on PubMed Central, MedLine, CAS, SciSearch ${ }^{\circledR}$, Current Contents ${ }^{\circledR} /$ Clinical Medicine,
56. Saraogi GK, Gupta P, Gupta UD, Jain NK, Agrawal GP. Gelatin nanocarriers as potential vectors for effective management of tuberculosis. Int J Pharm. 2010;385(1-2):143-149.

57. Tabata Y, Ikada Y. Effect of the size and surface charge of polymer microspheres on their phagocytosis by macrophage. Biomaterials. 1988; 9(4):356-362.

58. Hua S, Yang H, Wang W, Wang A. Controlled release of ofloxacin from chitosan-montmorillonite hydrogel. Appl Clay Sci. 2010;50(1): 112-117.

59. Mohanambe L, Vasudevan S. Inclusion of poly-aromatic hydrocarbon $(\mathrm{PAH})$ molecules in a functionalized layered double hydroxide. $J$ Chem Sci. 2006;118(1):105-115. Available from: http://www.ias. ac.in/chemsci/Pdf-Jan2006/105.pdf. Accessed August 1, 2012.

60. Akyuz S, Akyuz T. FT-IR and FT-Raman spectroscopic studies of adsorption of isoniazid by montmorillonite and saponite. Vib Spectrosc. 2008;48(2):229-232.

61. Hussein MZ, Al Ali SH, Zainal Z, Hakim MN. Development of antiproliferative nanohybrid compound with controlled release property using ellagic acid as the active agent. Int $J$ Nanomedicine. 2011;6: 1373-1383.

62. Hussein Al Ali SH, Al-Qubaisi M, Hussein MZ, Zainal Z, Hakim MN. Preparation of hippurate-zinc layered hydroxide nanohybrid and its synergistic effect with tamoxifen on HepG2 cell lines. Int J Nanomedicine. 2011;6:3099-3111.

63. Panchagnula R, Agrawal S. Biopharmaceutic and pharmacokinetic aspects of variable bioavailability of rifampicin. Int J Pharm. 2004; 271(1-2):1-4.

64. Monkhouse DC, Lach JL. Use of adsorbents in enhancement of drug dissolution. II. J Pharm Sci. 1972;61(9):1435-1491.

65. Brindley GW. X-ray and electron diffraction data for sepiolite. $A m$ Mineral. 1959;44:495-500.

66. Viçosa AL, Gomes AC, Soares BG, Paranhos CM. Effect of sepiolite on the physical properties and swelling behavior of rifampicin-loaded nanocomposite hydrogels. eXPRESS Polymer Letters. 2009;3:518-524.

67. Ruiz-Osuna C G-CR. Osteoarticular caseating tuberculosis of the hip: presenting as severe articular destruction. A case report. Acta Ortop Mex. 2008;22(4):254-258. Spanish.

68. Zhu M, Wang H, Liu J, et al. A mesoporous silica nanoparticulate/ $\beta$ $\mathrm{TCP} / \mathrm{BG}$ composite drug delivery system for osteoarticular tuberculosis therapy. Biomaterials. 2011;32(7):1986-1965.

69. Vallet Regí M, Ballas F, Arcos D. Mesoporous materials for drug delivery. Angew Chem Int Engl. 2007;46(40):7548-7558.

70. Mohanambe L, Vasudevan S. Orientational dynamics of anthracene in a cyclodextrin functionalized layered solid. J Phys Chem B. 2005; 109(24):11865-11869.

71. Global Protein Products, Inc. Zein: a natural biopolymer from a renewable resource [web page on the Internet]. Fairfield, ME: Global Protein Products, Inc; 2011. Available from: http://www.globalprotein.com/zein. html. Accessed August 1, 2012

72. S Benita, Microencapsulation: Methods and Industrial Applications. Marcel Dekkar, New York, 1996.

73. Ghanshyam V Joshi, Bhavesh D Kevadiya, Hasmukh A Patel, Hari C Bajaj, Raksh V Jasra. Montmorillonite as a drug delivery system: Intercalation and in vitro release of timolol maleate. International Journal of Pharmaceutics. 2009;374:53-57.

74. World Health Organization. Treatment of tuberculosis; Guidelines for national programme. WHO/CDS/TB; 2003.

Journal Citation Reports/Science Edition, EMBase, Scopus and the Elsevier Bibliographic databases. The manuscript management system is completely online and includes a very quick and fair peer-review system, which is all easy to use. Visit http://www.dovepress.com/ testimonials.php to read real quotes from published authors. 